\title{
La sanidad, la salubridad y el ornato público como técnicas jurídicas aplica- bles a la conservación de las ciudades*
}

\author{
Magdalena SuÁrez OJEDA \\ Profesora de Derecho Administrativo \\ Facultad de Ciencias de la Información. Universidad Complutense de Madrid
}

1. Consideraciones iniciales: El arte, la ciudad y el derecho.

La preocupación del ser humano por su entorno es consustancial a su misma naturaleza. Las formas de asentamiento que se han ido produciendo a lo largo de la historia e incluso de la prehistoria han sido fiel reflejo y elemento determinante para conocer, qué y cómo se hacía y con qué procedimientos. Indudablemente, afirmar que las civilizaciones plasman en las edificaciones el propio talante y talento es un asunto que no tiene discusión. Por ello, la historia es acompañada por los trabajos de los grandes tratadistas que comenzaron a efectuar significativas contribuciones escritas sobre la arquitectura y la planificación haciéndose eco de la importancia del patrimonio edilicio; no hay más que recordar a Palladio, Alberti, Serlio, Vignola, Prado y Villalpando, Ardemans, Vasari, Vitrubio por poner destacados ejemplos (Suarez, Lopezosa y Diaz, 2009).

\footnotetext{
* Texto revisado y actualizado de la ponencia presentada en las II Jornadas Arte y Ciudad celebradas en la Facultad de Ciencias de la Información de la UCM, Madrid, 23 y 24 de mayo de 2008.
} 
La ciudad aparte de su cometido primario de atender al cobijo de sus miembros tiene también una acepción política y social: es el lugar donde las personas se relacionan y establecen relaciones públicas (civitas griega o polis romana), o es un lugar doméstico y campestre (modelo nórdico) o una ciudad eminentemente privada y religiosa (Islam) o desestructurada como muchas ciudades actuales. Cada cultura ha ido incorporando su propia idiosincrasia pero al ser una obra siempre inacabada e imperfecta no está exenta de padecer males y contratiempos:

Pero esto, esta pretensión de convertir la ciudad en obra de arte, no alcanza más que a determinadas fases del acontecer humano. La ciudad en su integridad es muy pocas veces obra de una voluntad previamente establecida, y cuando esta voluntad llega a imponer un determinado sello, lo hace generalmente de una manera fragmentaria y episódica. (Chueca, 1989).

En todo caso, las ciudades se constituyen en símbolo de poder y tienden teleológicamente a la perdurabilidad de las obras, servicios e instalaciones. Nos encontramos ante un bien económico inelástico, que requiere unas fuertes inversiones y su correcto funcionamiento depende de un costoso y complejo sistema organizacional tanto público como privado, que requiere como es lógico, una articulación legislativa compleja en las que están concernidas todas las administraciones tanto estatal, como autonómica y local.

En el seno de las urbes conviven manifestaciones artísticas con productos menos originales o bellos, pero en su conjunto conforman una unidad, en ocasiones esas actuaciones son lesivas para el entorno (pantallas arquitectónicas en las playas), a veces componen un conjunto armónico cuando consigue combinar de modo equilibrado las edificaciones relevantes o menos significativas con aquellas que gozan de gran relevancia o particular encanto. Por ello, la regulación también tenderá a distinguir las unas de las otras estableciendo diferentes regímenes jurídicos.

No se puede olvidar que las ciudades siempre han sido y serán objeto de reflexión y producto del entendimiento de las relaciones sociales y necesidades de una época. Inventar ciudades de nueva planta como Brasilia (gran 
obra de Niemeyer) resulta una gran tentación para el ser humano semejante a la Torre de Babel o reconstruir ciudades azotadas por catástrofes como el nuevo Londres que surge después del gran incendio de 1666 o el terremoto que azotó Lisboa en 1755 y que permitió al Marqués de Pombal diseñar una ciudad abierta al Atlántico en su confluencia con el Tajo transida de grandes avenidas. Con todo, el gran paradigma de la ciudad reinventada o recreada para cumplir las nuevas exigencias del estado liberal desde un óptica higienista y propiciatoria de la seguridad y el centralismo, será siempre el París del barón Haussmann; con sus éxitos en la plaza de Charles De Gaulle (L'Etoile) y con sus fracasos al descontextualizar Notre Dame o la Saint-Chapelle.

\section{Evolución histórica de la conservación de las ciudades}

La conservación de los núcleos de población en nuestra legislación urbanística ha venido, desde sus comienzos, tradicionalmente ligado a la salubridad y el ornato (la seguridad nació más ligada a la ruina de los edificios). Las primeras regulaciones que fueron promulgadas en el siglo XVIII contenían dentro del ámbito de la policía urbana el cuidado de las ciudades, en un proceso de toma de conciencia para la formación de los intereses públicos diferenciados, y a veces no concomitantes con los privados, impulsores primarios de las actuaciones urbanísticas.

De esta forma, el ámbito municipal que se fue dotando de medios técnicos tales como la redacción de planes generales y proyectos de alineaciones (aparte de ejecuciones directas de obra), sufrieron un duro proceso de adaptación de las Ordenanzas a la legislación general que se dictaba y que fue mermando considerablemente sus competencias. A este ritmo surge también una estructura organizativa estatal. Pocos años después, empieza a calar en España la línea emprendida en el resto de Europa de abordar las grandes reformas urbanísticas de las grandes ciudades europeas. El proyecto de Ensanche, regularización y embellecimiento de la Puerta del Sol es un buen ejemplo de ello. Sufrió escollos tanto políticos (entre ellos tres cambios de gobierno y la vigencia de dos Constituciones distintas) como jurídicos propiciado en gran medida por la Ley de Expropiación Forzosa de 1836 que limitaba las expropiaciones a la implantación de las grandes vías de comunicación, pero resultaba insuficiente para abordar tareas tan complejas como la reforma interior que a 
efectos de dicha Ley tenían la consideración de meras obras de ornato y mejora, pero fuera de la declaración de utilidad pública a efectos de expropiación. La solución vino con la promulgación de una ley singular. A partir de mediados del siglo XIX el urbanismo comienza a perfilar los instrumentos para la consecución de sus grandes objetivos; el saneamiento y el ensanche.

Los problemas detectados en la Ley de expropiación forzosa de 1879 no se consiguieron resolver mediante una reforma global, se va a hacer de modo parcial, así la ley de 1895 obedece a esta sectorialización del instituto expropiatorio más que a una regulación urbanística de las áreas depauperadas de las ciudades, puesto que los temas de saneamiento y mejora propiamente dichos, fueron eliminados en el Senado quedando meramente como una legislación especial de expropiación. La Ley, fuertemente centralista, otorga por primera vez a los concesionarios privados bonificaciones y exenciones fiscales y preeminencia para ejecutar el saneamiento frente a los propios Ayuntamientos, que quedaban relegados a desempeñar funciones auxiliares de colaboración, eliminando así un instrumento modulador de la intervención publica de los intereses particulares. Fruto de la aplicación de esta medida son las reformas interiores llevadas a cabo en Barcelona (1881-1908), en la Gran Vía de Madrid (1901-1952), y en Granada (1890-1925).

Respecto a la expropiación; se tuvo en cuenta los derechos de inquilinos, comerciantes e industriales, se crea el Jurado de expropiación, órgano decisorio aglutinador de las distintas voluntades sociales implicadas en los procesos de fijación de las indemnizaciones expropiatorias. Es fundamental resaltar a estos efectos que no se enunció el deber de mejorar o sanear fincas o edificios en manos de particulares, a pesar de lo cual se regula la expropiación para eliminar todo aquello que no cumpla con la función prevista. Por otro lado, se fueron sentando las bases sobre la regulación de clasificación y ancho de calles, altura de las casas y distribución de pisos (Orden de 2 de agosto de 1861). La tendencia que se apuntaba residía en ir desbrozando la difícil tarea de las alineaciones, ejemplo es la Real Orden de 26 de octubre de 1864 eliminó el derecho a recibir indemnización por este motivo y la Real Orden de 12 de marzo de 1878 que impidió la realización de obras de consolidación en aquellos edificios que están fuera de ordenación (Bassols, 1973). 
En 1889 se aprueba el Código Civil que aunque pasa por alto la regulación de la propiedad urbanística, sí introduce dos técnicas propias de éste ámbito; las servidumbres y los reglamentos de policía. Y se establece también, en aras a la seguridad de los edificios, el principio de responsabilidad del propietario por falta de cuidado, junto con la obligación de realizar las reparaciones necesarias y en su caso la demolición del edificio en mal estado (arts. 389 y 1097 del Código Civil). El impulso mayor para la regulación del saneamiento se va a concretar definitivamente en la redacción de las diversas ordenanzas municipales que se van aprobando a partir de mediados de siglo (Madrid 1847, Barcelona 1856). Aparte de las aportaciones de la Junta Consultiva de Policía Urbana, dependiente del Ministerio de la Gobernación. Nuevos vientos soplan a partir de principio de siglo XX, que nace ligando la historia del urbanismo con las cuestiones sanitarias propiamente dichas. De tal forma que se empieza a demostrar auténtica preocupación por el saneamiento de poblaciones en lucha contra las epidemias y enfermedades, al contrario que el resto de Europa, que una vez remozados los cascos de las ciudades más importantes emprendían la aventura del ensanche.

A partir de la mitad del siglo pasado nos vamos encontrando con numerosa legislación del suelo que va a destinar parte de su articulado a la regulación de la regeneración de las ciudades, medidas que se verán acompañadas por regulaciones dadas por leyes de patrimonio histórico y protección del medio ambiente urbano, que transcenderán sin duda a la primera línea más ligada a la garantía de condiciones sanitarias. A lo que habrá que acompañar el desarrollo de técnicas más precisas a la hora de la rehabilitación de edificios, tanto desde un punto de vista singular como desde la óptica del conjunto o entorno. La Ley del Suelo de 1956 es un texto emblemático de excelente factura técnica-jurídica que permite residenciar en la planificación el sustento de toda actuación pública (García de Enterria, Parejo, 1981)

\section{La seguridad, salubridad y ornato público en las regulaciones recientes.}

La cuestión de la conservación de las ciudades ha sido, pues, una constante que tiene su continuación en la Ley 8/2007, de 28 de mayo, del Suelo que recogía la obligación de que la posterior legislación elaborará un Texto Refundido que incluyera determinados deberes para propietarios incluidos: 
El derecho de propiedad del suelo comprende, cualquiera que sea la situación en que éste se encuentre y sin perjuicio del régimen al que esté sometido por razón de su clasificación, los deberes de dedicarlo a usos que no sean incompatibles con la ordenación territorial y urbanística; conservarlo en las condiciones legales para servir de soporte a dicho uso y, en todo caso, en las de seguridad, salubridad, accesibilidad y ornato legalmente exigibles; así como realizar los trabajos de mejora y rehabilitación hasta donde alcance el deber legal de conservación. (Art. 9.1 Ley 8/2007)

$\mathrm{Al}$ amparo de esta norma de delegación se aprueba el vigente Real Decreto Legislativo 2/2008, de 20 de junio, por el que se aprueba el Texto Refundido de la Ley de Suelo. En su artículo 9 establece el contenido del derecho de propiedad del suelo:

1. El derecho de propiedad de los terrenos, las instalaciones, construcciones y edificaciones, comprende, cualquiera que sea la situación en que se encuentren, los deberes de dedicarlos a usos que no sean incompatibles con la ordenación territorial y urbanística; conservarlos en las condiciones legales para servir de soporte a dicho uso y, en todo caso, en las de seguridad, salubridad, accesibilidad y ornato legalmente exigibles; así como realizar los trabajos de mejora y rehabilitación hasta donde alcance el deber legal de conservación. Este deber constituirá el límite de las obras que deban ejecutarse a costa de los propietarios, cuando la Administración las ordene por motivos turísticos o culturales, corriendo a cargo de los fondos de ésta las obras que lo rebasen para obtener mejoras de interés general.

Norma vigente, que tiene su precedente inmediato en la ya derogada Ley 6/1998, de 13 de abril, sobre régimen del suelo y valoraciones vigente hasta hace pocas fechas es nuestro precedente inmediato (Fernandez, 2008) y establecía lo siguiente:

Art. 19. Deberes legales de uso, conservación y rehabilitación. 1) Los propietarios de toda clase de terrenos y construcciones deberán destinarlos a usos que no resulten incompatibles con el planeamiento urbanístico y mantenerlos en condiciones de seguridad, salubridad y ornato público. Quedarán sujetos igualmente 
al cumplimiento de las normas sobre protección del medio ambiente y de los patrimonios arquitectónicos y arqueológicos y sobre rehabilitación urbana.

De tal manera que todas las leyes del Suelo estatales desde la Ley del Suelo de 1956 hasta nuestros días han introducido invariablemente estas tres categorías predicables del deber de conservación: la seguridad, la salubridad y el ornato. Resulta relevante resaltar, que independientemente del signo político que hayan impulsado los diferentes proyectos de leyes del suelo de elaboración previa a la posterior promulgación parlamentaria han resultado invariable, en su orden y terminología exacta la introducción de estos tres conceptos como base de los deberes de los propietarios de suelo, edificaciones y construcciones (ello aunque se hayan dado distinto tipo de soluciones jurídicas al costeamiento de las obras y otras cuestiones desde luego trascendentes para la conformación del régimen jurídico aplicable).

También es necesario hacer notar que se han enunciado por este orden desde el principio. Según creo esto no es una cuestión baladí. Sólo la actualmente norma vigente ha introducido entre salubridad y ornato la accesibilidad. Otras leyes anteriores también hicieron referencia al deber de rehabilitar, conservar el patrimonio arquitectónico y arqueológico y el medio ambiente. Creo que ello es así tanto por la conformación histórica de la cual traen causa estas tres categorías, por un lado, y además por la importancia que cada una de las tres tiene de cara al interés público y al bienestar social. Y ello por lo siguiente: La seguridad hace referencia a la necesidad de que el suelo, la construcción o la edificación se mantenga en condiciones apropiadas para evitar accidentes que puedan dañar a personas o cosas. Nótese la importancia que tiene mantener las cornisas o voladizos de una forma correcta para evitar que se desprendan. Pero hay otras cuestiones de mayor calado aún; las que se refieren a la detección de los estados de ruina y la declaración de demolición de la edificación como exponente máximo de la necesidad de intervención pública en este sector.

Si hablamos de las ciudades en su conjunto es obligado resaltar la importancia de las planificaciones (planos de alineaciones en un primer momento) para garantizar la seguridad pública y prevenir delitos, revueltas y algaradas. 
Cuando se habla de salubridad se hace referencia, sin duda, a toda una línea higienista que buscaba solventar los graves problemas estructurales que tenían tanto las viviendas como las ciudades y que eran la causa de la propagación de grandes epidemias y endemias que azotaron Europa, tanto en la época medieval como en la edad moderna, y que supusieron auténticos estragos desde el punto de vista demográfico. La falta de saneamiento general propiciaba en grado máximo su expansión (recuérdese las grandes epidemias de pestes o gripes de asolaron Europa).

Con posterioridad, el descubrimiento de nuevos sistemas de construcción, el desarrollo de las obras públicas, la instalación de servicios públicos como el abastecimiento de agua potable domiciliaria, el alumbrado público, el alcantarillado, la gestión de residuos sólidos urbanos, entre otros han sido la causa clara del desarrollo exponencial de las urbes.

Desde el punto de vista singular la adquisición de servicios por parte del patrimonio edificatorio en su conjunto fue un proceso lento, tanto por que la necesidad de adecuación por parte de determinadas construcciones fue imposible en algunos casos, y se tuvieron que sustituir muchos edificios por otros con de mejor calidad, tanto porque en todo caso se tuvo que emprender el gran proceso de regeneración de la ciudad por la que las viviendas pasaban a ser más altas, con más luz y con más servicios.

Finalmente el ornato (en la legislación anterior se hablaba de ornato público) es el deber que tiene todo propietario de garantizar que al menos la fachada, lo externo y visible de su edificación, esté dignamente mantenido y sea visualmente si no bello, sí decente y bien cuidado. Bien es verdad que las legislaciones han ido reflejando la necesidad de participar en tareas de engalanamiento o de cuestiones relativas a mejoras de impacto general en determinados casos como pueda ser en municipios turísticos en los que el grado de preservación ha de ser mayor. Ocurre lo mismo con las construcciones declaradas patrimonio histórico-artístico, ya que tanto el monumento como el entorno va a gozar de una protección especial que excede al concepto de ornato proporcionado por la legislación urbanística para residenciar las cuestiones relativas a su regulación jurídica en leyes particularmente protectoras. 
En la actualidad cobra importancia creciente también el concepto de accesibilidad tanto edificatoria, como urbanística, en el transporte y en los soportes virtuales, como método imprescindible para que la ciudad cumpla el cometido básico de atender a su funcionalidad en todas las etapas de la vida y para todas las personas (Suárez, 2008: 53).

\section{El valor medioambiental incorporado a la categoría de conservación ur- banística.}

Verdaderamente estas categorías incorporan un principio general de conservación y se aplican preferentemente al suelo ya urbano. Pero en la actualidad, y desde hace varias décadas, el urbanismo no puede entenderse escindido del contexto en el que se desarrolla, por ello, el medio ambiente ha venido a transformar las perspectivas desarrollistas del urbanismo de otras décadas tornando en preocupación por la preservación de los espacios, su mejora y su adaptación a la vida y a las circunstancias del momento.

De este modo se promueve que el desarrollo urbano sea sostenible, exigiendo a los particulares la necesidad de Respetar y contribuir a preservar el medio ambiente, el patrimonio histórico y el paisaje natural y urbano, absteniéndose en todo caso de realizar cualquier acto o desarrollar cualquier actividad no permitidos por la legislación en la materia. (art. 5a. Ley del Suelo 2008).

Esta preocupación no nace en solitario y de la nada, surge como consecuencia de los múltiples riesgos ambientales que se empiezan a crear en las ciudades como consecuencia de la realización de actividades molestas, nocivas y peligrosas, es producto pues, de la revolución industrial y postindustrial, e incorporado a los ordenamientos jurídicos a partir de los años 70 en España. Nuestra incorporación a las entonces Comunidades Económicas en 1986 -hoy Unión Europea- hizo que esta disciplina inundara todas las materias concomitantes, transformándolas de modo indeleble. En la actualidad las políticas comunitarias discurren por el eje de

La lucha contra el cambio climático, mantener la biodiversidad, reducir los problemas de salud derivados de la contaminación y utilizar los recursos naturales de manera más responsable. Estos objetivos van encaminados a proteger el me- 
dio ambiente, pero pueden contribuir asimismo al crecimiento económico impulsando la innovación y la empresa. (http://europa.eu/pol/env/index_es.htm).

Pero desde luego en este terreno resulta definitoria la Comunicación de la Comisión, de 11 de enero de 2006, sobre una Estrategia temática para el medio ambiente urbano ${ }^{1}$. Este documento tiene por objeto mejorar la calidad del medio ambiente urbano, convirtiendo las ciudades en lugares de vida, trabajo e inversión más atractivos y sanos, y reduciendo el impacto medioambiental negativo de las aglomeraciones. Las principales medidas previstas por la estrategia son'2:

- La publicación de orientaciones relativas a la integración de las cuestiones medioambientales en las políticas urbanas. Estas orientaciones se basarán en las mejores prácticas y los dictámenes de expertos. Una gestión medioambiental integrada permitirá una mejor planificación y evitar los conflictos entre distintas medidas;

- La publicación de orientaciones sobre planes de transporte urbano sostenible. Estas orientaciones se basarán también en las mejores prácticas y los dictámenes de expertos. Una planificación eficaz de los transportes debe tener en cuenta tanto a las personas como a las mercancías y promover la utilización segura y eficaz de medios de transporte poco contaminantes y de calidad;

- El apoyo al intercambio de las mejores prácticas mediante la conexión en red de la información, el desarrollo de proyectos de demostración financiados por LIFE+ y el establecimiento de una red de puntos de contacto nacionales;

- El refuerzo de la información de las administraciones locales mediante Internet y de la formación de los trabajadores de las administraciones regionales y locales en cuestiones de gestión urbana;

- La utilización de los programas comunitarios de ayuda que existen en el marco de la política de cohesión e investigación.

${ }^{1}$ COM (2005) 718 final, no publicada en el Diario Oficial.

${ }^{2} \mathrm{http}$ //europa.eu/legislation_summaries/environment/sustainable_development/128171_es.htm 
Por todo ello, bien puede decirse que el medio ambiente viene a reformular las técnicas propuestas por el urbanismo, proponiendo nuevos mecanismo para conseguir la sostenibilidad y propiciando el consumo responsable. Siendo prevalente las consideraciones medioambientalistas al desarrollo urbano, al menos en teoría. Aunque el punto último de ampliación de esta política comunitaria sea la ciudad no es menos cierto que es un elemento clave en sus líneas de actuación futura.

\section{5. ¿Ha desaparecido la preocupación por lo bello o el derecho lo desconoce y se inclina solo por lo útil y eficiente?}

El Derecho en el ámbito urbanístico es hiperregulacionista. La profusión de normas publicadas en los últimos años en lo referente a este campo ocupan estanterías enteras, Independientemente de éste fenómeno, es obligado señalar que el Derecho Público -en particular el derecho municipal- ha establecido la necesidad de establecer un marco de referencia general y estricto para las urbanizaciones, edificaciones, y construcciones en general, en todas la regulación histórica, como hemos visto.

En la actualidad, y desde la aprobación de la Constitución de 1978, habida cuenta que los aspectos conservativos son competencia fundamentalmente de las Comunidades Autónomas, habrá que acudir a la legislación propia de cada una de las diez y siete entidades y además a sus respectivos planes municipales de urbanismo para saber cual es el régimen jurídico aplicable a cada urbe. Ello nos plantea la cuestión de si tanta regulación junto con la evolución de los sistemas informáticos ha llevado a la eliminación de la singularidad de los espacios urbanos.

La práctica desaparición de la arquitectura de la escuadra y cartabón ha hecho mella en las ciudades, la mayoría de los edificios carecen ahora de cierta gracia distintiva y el aporte del "artista" a la obra, en la mayoría de los casos la funcionalidad del edificio, la eficiencia energética, la accesibilidad, la preservación de contaminación acústica y cuestiones de esta índole hacen decaer la belleza de la misma, a lo que se le une las exigencias técnicas incluidas en dichos planes de urbanismo, en la Ley de Ordenación de la Edificación y el Código Técnico de la Edificación. 
En fin, el derecho valora, desde luego lo bello y lo perenne -más cuando se aúnan ambos méritos- de ahí la regulación proporcionada por la Ley de Patrimonio Histórico. Cierto es que se fomenta la arquitectura singular y creativa, pero normalmente está referida a obras muy concretas normalmente acompañadas de intervenciones públicas de calado las que van aportando peculiaridad a las ciudades. En el urbanismo actual permanece la tendencia de engrandecer las ciudades introduciendo elementos que les doten de signos distintivos, que sean al mismo tiempo icono de la propia urbe y elemento de atracción de personas de otros lugares (ampliación del Museo del Prado en Madrid hecha por Rafael Moneo, construcción del Museo Guggenhgeim Bilbao de Frank Gehry).

Ello no es nada novedoso, más bien es una cuestión arraigada en el tiempo y se presenta como una costumbre inveterada -piénsese en lo definitorio que es la Torre Eiffel para París, la Torre del Oro para Sevilla o la Torre de Pisa o el Coliseo para Roma o la Acrópolis para Atenas-. Poseen pues, todos ellos rasgos identitarios de una época, y se configuran y permanecen como símbolos de superación y elementos incluso de poder económico y político. En ocasiones, la relevancia puede ir más allá de una obra, de modo tal que la ciudad quede impregnada en su conjunto por la contribución de grandes arquitectos o diseñadores como Gaudí en Barcelona, Manrique en Lanzarote o Calatrava en Valencia.

Creo que junto con el diseño de la ciudad (planificación), ejecución de las obras de urbanización (gestión) y cuidado del orden y conservación de las edificaciones (disciplina), hay una serie de elementos en las ciudades que son piezas singulares procedentes del legado de generaciones anteriores o bien elementos que introducen de modo novedoso e incluso experimental. De tal modo que, en toda ciudad grande o mediana y en algunos pueblos, suele haber algún monumento digno de mención.

\section{Conclusión}

En conclusión a este trabajo puede decirse que los conceptos de seguridad, salubridad y ornato han sido y son piezas claves para entender la conservación de las ciudades tanto desde el punto de vista general como singular. A lo 
que hay que añadir las grandes obras de personas relevantes que dan perfiles característicos a cada urbe. Bien puede afirmarse pues, que cada ciudad es una sublimación de los que la habitan, la piensan y la hacen conformando el entorno y relacionándose con el medio, en ella se refleja nuestro pasado, se vive el presente y se diseña el futuro.

\section{BIBLIOGRAFÍA}

BASSOls COMA, Martín (1973). Génesis y evolución del Derecho Urbanístico español (1812-1956). Madrid, Montecovo.

CONSEJO GENERAL DEL PODER JUDICIAL (2004). Derecho y urbanismo: principios e instituciones comunes. Madrid, Cuadernos de Derecho Judicial.

CAPEL, Horacio. (1990) Capitalismo y morfología urbana en España. Circulo de Lectores. Barcelona.

CHUECA Goitia, Fernando (1989). Breve Historia del Urbanismo. Madrid, Alianza Editorial.

CUYÁs PALAZÓN, María Mercedes (2007). Urbanismo ambiental y evaluación estratégica: adaptado a la Ley 8/2007 del suelo y a la Ley 9/2006 sobre evaluación de los efectos de determinados planes y programas en el medio ambiente. Barcelona, Atellier.

FERNÁNDEZ RODRÍGUEZ, Tomás Ramón (2008). Manual de Derecho Urbanístico. Madrid, La Ley, El Consultor de los Ayuntamientos.

GARCía De ENTERrÍA, Eduardo y PAREJO AlFONSO, Luciano (1981). Lecciones de Derecho Urbanístico. Madrid, Civitas.

LORA-TAMAyo VAlLVÉ, Marta (2007). Historia de la legislación urbanística. Madrid, Iustel.

LORA-TAMAyO VAllvé, Marta (2006). Derecho urbanístico y medio ambiente: hacia un desarrollo urbano sostenible. Madrid, Dykinson.

SuAReZ Quevedo, Diego, LOPEZOSA APARICIO, Concepción, DíAZ Moreno, Félix (ed). (2009) Arquitectura y ciudad. Memoria e imprenta. Madrid, Universidad Complutense de Madrid.

SuAREZ OJEDA, Magdalena. (2008) "La accesibilidad en la edificación: reflexión general y nuevas perspectivas" Revista de Urbanismo y Edificación, $\mathrm{n}^{\mathrm{o}}$ 48, págs. 53-66. 
PAREJO AlFONSO, Luciano (1979). La ordenación urbanística. El período 19561975. Madrid, Montecovo.

QUINTANA LÓPEZ, Tomás. (2001). Derecho Urbanístico estatal y autonómico. Valencia, Tirant lo Blanch. 